\title{
Stimulus control of behavior induced by a periodic schedule of food presentation in pigeons
}

\author{
CAROL BLAINE and NANCY K. INNIS \\ University of Western Ontario, London, Ontario N6A 5C2, Canada \\ and \\ J. E. R. STADDON \\ Duke University, Durham, North Carolina 27706
}

\begin{abstract}
Four pigeons were exposed to a fixed-time (FT) 27-sec schedule of food presentation in a large chamber partitioned into several areas. Each area provided different environmental support stimuli, such as water, nesting material, or the opportunity to observe another bird. A stereotyped pattern of behavior developed, with the birds leaving the food area early in intervals (interim activity) and returning to perform a food-related behavior (terminal response) toward the end of intervals. Unlike rats under similar conditions, the pigeons' interim activities did not seem to be under the direct control of environmental stimuli. Early in intervals, the birds simply turned and walked away from the food area for a few seconds, before returning to perform the terminal response.
\end{abstract}

When food is presented to hungry pigeons at regular intervals, as on a fixed-time (FT) reinforcement schedule, a stereotyped pattern of responding develops during the interfood intervals (Reberg, Innis, Mann, \& Eizenga, 1978; Staddon \& Simmelhag, 1971). Staddon and Simmelhag suggested that two distinct classes of behavior are evident in this pattern, interim activities and a terminal response. The terminal response occurs during the final seconds of intervals and typically resembles the consummatory feeding response (pecking with open beak). Interim activities, on the other hand, occur early in intervals, usually take the bird away from the feeding area, are often incompatible with the terminal response, and may reflect a competing motivational state (cf. Staddon, 1977).

The findings of Staddon and Simmelhag (1971) were extended by Staddon and Ayres (1975) in a study in which they examined the kinds of interim activities induced on an FT 30-sec schedule of food presentation in rats. The rats were studied in a large enclosure that permitted access to several discrete areas and activities, such as drinking and wheel running. Both drinking and wheel running occurred with high frequencies early in intervals (interim activities), with a terminal response of going to the feeder area in anticipation of food appearing late in intervals. Similar findings have also been reported by Mann (1975).

This research was supported by Natural Sciences and Engineering Research Council of Canada Grant A-9945 to N. K. Innis. We thank Kenneth Coulter for his assistance in carrying out the experiment and Joan Burns and Susan Gammon for assistance in assessing rater reliability. Reprints may be obtained from Nancy K. Innis, Department of Psychology, University of Western Ontario, London, Ontario N6A 5C2 Canada.
In order to determine the effect of environmental stimuli on the development of schedule-induced behavior patterns in pigeons, four birds were exposed to an FT 27-sec schedule of food presentation in a large enclosure that permitted movement to several areas and access to several stimuli.

\section{METHOD}

\section{Subjects}

The subjects were four experimentally naive White Carneaux pigeons, two adult females $(44 \mathrm{~F}$ and $50 \mathrm{~F})$ and two young adults, a male (48M) and a female $(31 \mathrm{~F})$, the offspring of $44 \mathrm{~F}$. Two adult male pigeons, a White Carneaux $(44 \mathrm{M}$, the mate of 44F) and a Silver King, were used as stimulus birds. During Phases 2 and 3 of the study, the experimental subjects were maintained at $80 \%$ of free-feeding weights by limiting access to food. The stimulus birds and the experimental birds in Phase 1 had free access to food in their home cages. Water was always freely available, and the housing room was maintained on a 12-h/12-h light-dark cycle.

\section{Apparatus}

A top view of the experimental chamber, a large $(61 \mathrm{x}$ $72.2 \times 43.2 \mathrm{~cm}$ ) box fitted with a plywood insert that divided the space into seven areas, is shown in Figure 1. The vertical partitions separating the areas were $15.2 \mathrm{~cm}$ deep and $30.5 \mathrm{~cm}$ high. The two walls adjoining the observation areas were constructed of Plexiglas, perforated in the sections adjacent to the holding cages by small holes to facilitate the transmission of auditory and olfactory cues from the stimulus birds. In the perch area, a dowel perch, located $20.3 \mathrm{~cm}$ above the floor, extended across the corner from the wooden back wall to the Plexiglas side wall. In the nest area, various sizes of twigs and pine needles were placed in a small glass bowl taped to the floor. A Gerbrands' pigeon feeder was mounted behind the aluminum (left) wall adjacent to the food area, and a similar hopper, which had been modified to contain water, was mounted on this wall in the water area. The apertures in the wall permitting access to food or water were $5.7 \mathrm{~cm}$ above the floor. The hexagonal 


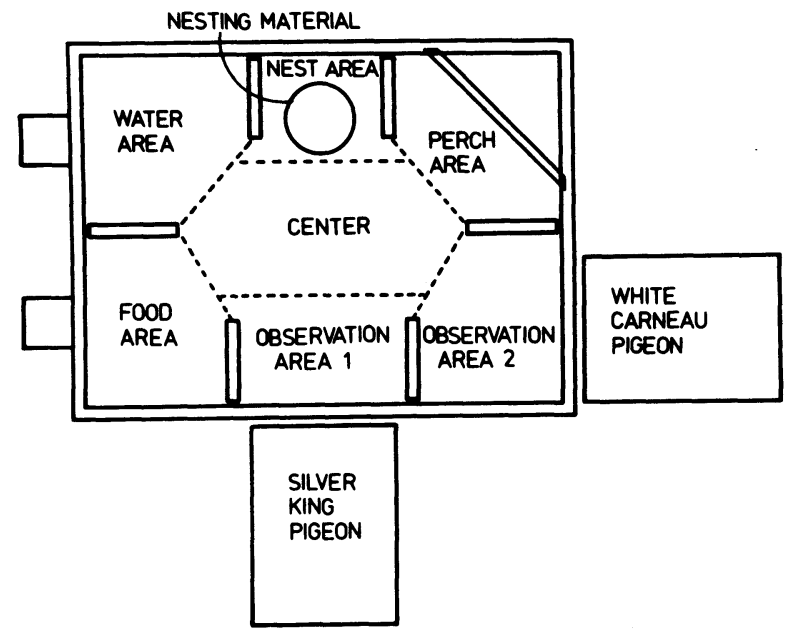

Figure 1. An overhead view of the experimental chamber.

center area was formed by drawing lines on the floor of the box between the partitions, as shown in Figure 1.

A Sony TV camera was suspended from the ceiling above the apparatus, and the experimenter observed the birds on a video monitor located at the opposite end of the experimental room, where the scheduling and recording equipment was also located. Data were recorded on running timers and on an eight-pen Rustrak event recorder controlled manually by a panel of pushbuttons. Occasional sessions were videotaped for further analysis. The room was always brightly illuminated by fluorescent ceiling lamps.

\section{Procedure}

There were three phases in the experiment. Initially, the birds were maintained at $100 \%$ of free-feeding weights and placed in the apparatus (in the center area) for six daily 45-min sessions: a nondeprived baseline condition. No food was available, but the birds had free access to water. The tray of the water hopper was held up, and it was illuminated by a light inside the hopper. During the second phase of the study, a deprived baseline condition, the birds were reduced to $85 \%$ of free-feeding weights and then placed in the chamber for six daily 30-min sessions. During these sessions, the feeder tray, containing $15 \mathrm{~g}$ of mixed grain, was held upright throughout the session. A constant supply of water was always available. In the final, schedule phase, the birds received brief $(3-\mathrm{sec})$ access to food every $27 \mathrm{sec}$, a FT $27-\mathrm{sec}$ schedule of food delivery. There were 60 food presentations during each of the 20 consecutive 30 -min sessions. As in the previous phases, water was available at all times.

\section{Data Recording}

The location and the activity of the birds were recorded on the event recorder for each second of all sessions. Location was defined as the bird's being positioned so that over half of its body was in a given area. The total amount of time spent in each area during a session was recorded on running-time meters.

In order to assess the reliability of the experimenter's (C.B.) observations, two independent observers were trained on a practice tape to use the recording devices, and then each recorded the data for the final session of two of the birds. Correlations between the experimenter and each rater were .99 for the location scores and .98 for the activity scores.

\section{RESULTS}

Mean time spent in each area of the chamber during the first two phases and the first and last six sessions of the final phase of the experiment are shown in Figure 2. Data are plotted as proportions of total session time, which were $45 \mathrm{~min}$ in Phase 1 and $30 \mathrm{~min}$ in subsequent phases. The birds rarely entered the water, nest, or perch areas, so these data are not included in the figure. During Phase 1, all birds spent a large amount of time in the center area. Bird 50F, in fact, did not move from this area at all during the 6 days of this condition; she usually remained still, engaging occasionally in preening responses. The two juvenile birds $(31 \mathrm{~F}$ and $48 \mathrm{M})$ spent a substantial amount of time in Observation Area 2, adjacent to the male White Carneaux pigeon (their father). Occasional pecking responses at the Plexiglas wall were recorded.

When food was introduced in Phase 2, all birds spent less time in the center area and more time in the food area than in the previous condition. By the end of this phase, the typical pattern was for birds to go to the food area as soon as they were placed in the center area of the chamber and remain there until they had consumed all the food. The birds then returned to the center area and, with the exception of Bird $50 \mathrm{~F}$, spent some time in either or both the observation areas. All birds also returned to the food area for brief visits later in sessions, often poking their heads in the feeder aperture.

During the final phase, when food was presented on a regular schedule, time spent in the food area increased substantially for all birds almost immediately, and the total amount of time spent in this area did not change noticeably across the 20 days of the condition. The pattern of behavior did change, however, and these data are shown in Figure 3.

Presence in an area as a function of postfood time

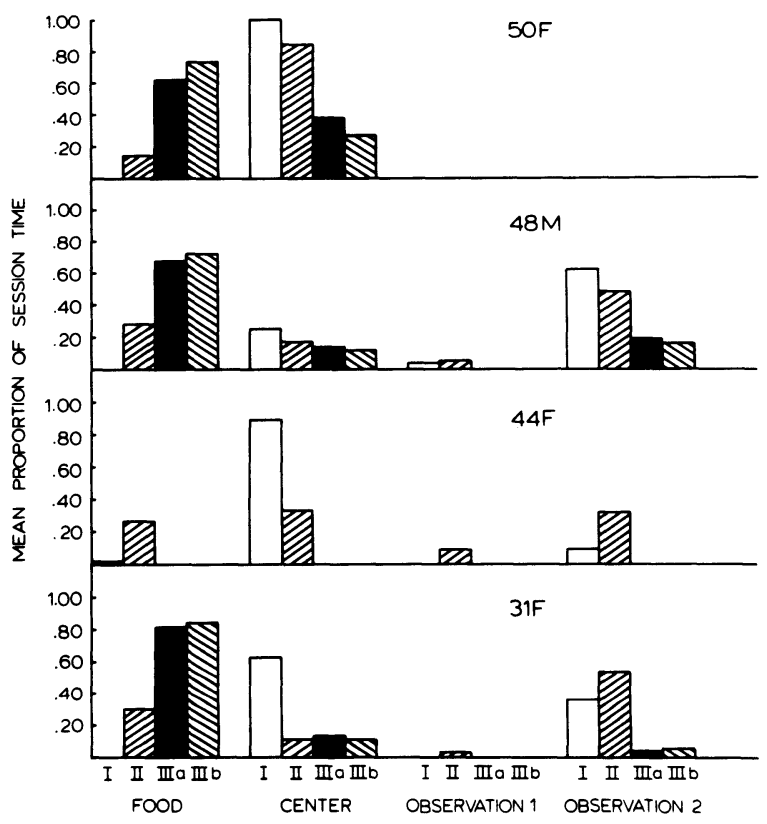

Figure 2. Mean proportion of session time spent in the food area, center area, and Observation Areas 1 and 2 by each bird during the six sessions of Phases 1 and 2 and the first and last six sessions of Phase 3, labeled a and b, respectively. 


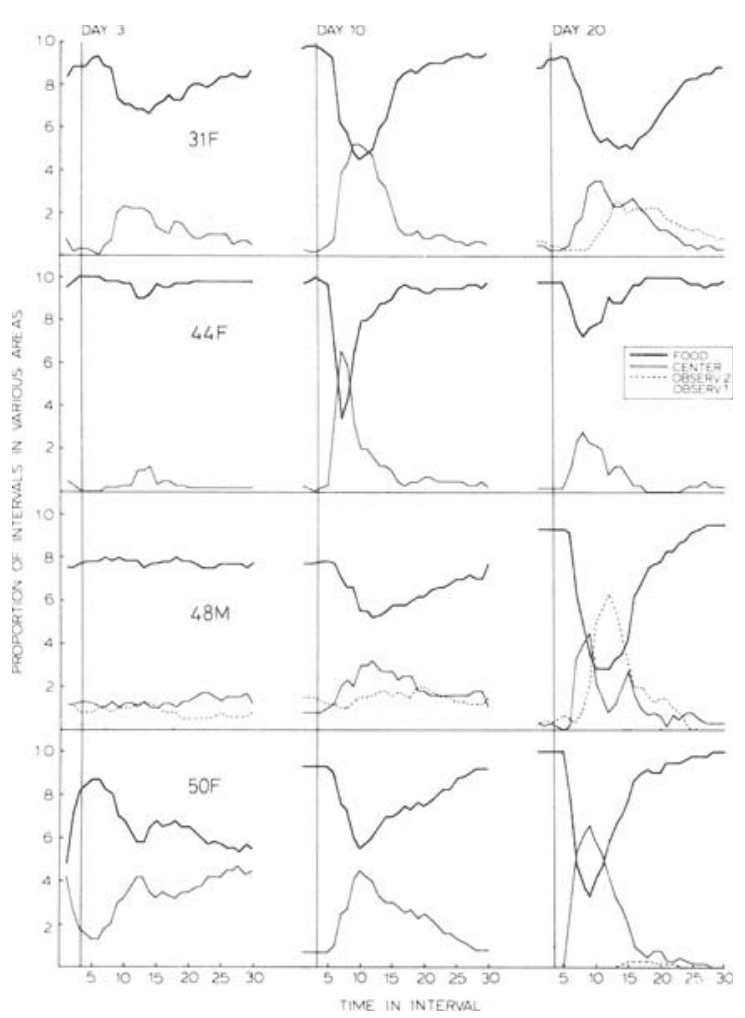

Figure 3. Probability of being in a particular area during each second of the 3-sec food presentation (to left of vertical line) and of the 27 -sec interfood interval for each bird during Sessions 3, 10, and 20 of Phase 3. Each data point represents the proportion of a possible 60 intervals in which a bird was located in a particular area.

for each bird during Sessions 3, 10, and 20 of Phase 3 are presented in Figure 3. Early in the condition, time spent in an area was relatively constant across the 27 -sec interval, and occasional feedings were missed if a bird was not in the feeder area when food was presented. By Session 10, the birds were almost always in the food area just prior to food presentation. Just after food presentation, brief excursions to the center area, and for Bird $48 \mathrm{M}$, to Observation Area 2, were made on a large number of intervals. This pattern was more evident by Session 20, when both Birds $31 \mathrm{~F}$ and $48 \mathrm{M}$ typically moved from the food area through the center area to the observation area and then back to the food area in the first half of the interval. Other areas rarely, if ever, were entered.

In terms of activity, the birds did not directly interact with the available stimuli, with the possible exception of Bird 48M in Observation Area 2. No bird drank, sat on the perch, nested, or moved the twigs. Occasionally, a bird entered Observation Area 1, but few if any responses were directed at the Silver King pigeon, even though this bird frequently thrashed around in his cage, making a good deal of noise. While the offspring of Bird $44 \mathrm{M}$ frequently entered the area adjacent to his cage, there was generally little pecking directed at him. On some intervals, Bird 48M would run into this area, eliciting loud cooing responses from the observation bird. Bird 48M did not coo in response, and although the cooing of the adult bird often continued for several intervals, Bird 48M's behavior pattern was rarely disrupted.

While in the food area, late in intervals, each bird showed a distinctive activity. Bird 50 paced along the feeder wall, occasionally wing flapping or pecking at the wall. Bird 48 was less active, spending a lot of time pecking with considerable force at the wall or the hopper. Bird 31 stood still and pecked at the hopper, and Bird 44 made head movements to the side wall to the left of the feeder, occasionally pecking it.

To summarize, all birds left the feeder area on a large proportion of intervals. The typical pattern was to turn from the food area and stand in the center area, or in some cases in Observation Area 2, facing away from the feeder. After a few seconds, the birds returned to the food area and directed their behavior at the feeder wall, or the feeder itself, until food was presented.

\section{DISCUSSION}

Staddon (1977; Staddon \& Simmelhag, 1971) has suggested that brief periodic presentations of food to hungry animals result in the induction of two types of behavior. Late in intervals, when the probability of food presentation is high, a foodrelated terminal response is induced. Early in intervals at times uncorrelated with food presentation, interim activities, related to nonfood motivational states, occur. In rats, these interim activities include drinking, air licking, and wheel running (Mann, 1975; Staddon \& Ayres, 1975). In the experiment reported here, pigeons were exposed to an FT 27-sec schedule of food presentation in a large chamber that provided access to a number of environmental stimuli. Although a stereotyped pattern of responding, ending with a terminal response, developed during interfood intervals, the pigeons, unlike rats, did not develop interim activities directly controlled by environmental stimuli. Early in intervals, the birds simply turned away from the feeder and moved to the center area and, for two birds, to the observation area directly opposite the feeder. This response was very similar to the "down-and-back" response reported by Reberg et al. (1978), in which pigeons studied in a long box briefly left the food area, visited the water area, and returned to the food area during interfood intervals. In the long-box situation, it was unclear if birds were attracted to the water area or were avoiding the food area during these "down-and-back" excursions. The present data suggest that the birds were simply moving away from the food area.

Two birds typically moved to the observation area directly opposite the food area and stood facing the male pigeon (their father) housed there. Although the male juvenile subject, $48 \mathrm{M}$, would occasionally run into this area, neither bird displayed typical aggressive postures such as wing raising or puffing out the breast feathers, and few pecks were directed at the observation bird. These data suggest that nonfood motivational states, such as thirst or aggression, may not be induced in pigeons, as they are in rats, on these periodic schedules of food presentation. Further research is necessary to determine if this is a real species difference or if the differences obtained were the result of presenting stimuli inadequate for the support of interim behavior. 


\section{REFERENCES}

$\mathrm{M}_{\mathrm{ANN}}, \mathrm{B}$. E. The effect of response-independent food and water reinforcers on superstitious responding in the rat. Unpublished masters' thesis, University of Western Ontario, 1975.

Reberg, D., Innis, N. K., Mann, B., \& Eizenga, C. “Superstitious" behaviors resulting from periodic response-independent presentations of food or water. Animal Behaviour, 1978, 28, 507-519.

Staddon, J. E. R. Schedule-induced behavior. In W. K. Honig
\& J. E. R. Staddon (Eds.), Handbook of operant behavior. Englewood Cliffs, N. J.: Prentice-Hall, 1977.

Staddon, J. E. R., \& Ayres, S. L. Sequential and temporal properties of behavior induced by a schedule of periodic food delivery. Behaviour, 1975, 54, 26-49.

Staddon, J. E. R., \& Simmelihag, V. L. The "superstition" experiment: A reexamination of its implications for the principles of adaptive behavior. Psychological Review, 1971, 78, 3-43.

(Received for publication July 8, 1980.) 